\title{
Amiodarone-induced myxoedema coma as a rare differential diagnosis of consciousness disturbance
}

\author{
Cláudio Martins $^{* 1}$, Clara Rosa ${ }^{2}$, Ana Paula Oliveira ${ }^{1}$ \\ ${ }^{1}$ Department of Gastroenterology, Setúbal Hospital Center, São Bernardo Hospital, Setúbal, Portugal \\ ${ }^{2}$ Department of Internal Medicine, Setúbal Hospital Center, São Bernardo Hospital, Setúbal, Portugal
}

Received: October 23, 2016

DOI: $10.5430 /$ crim.v4n1p42
Accepted: December 22, 2016 Online Published: January 5, 2017

URL: https://doi.org/10.5430/crim.v4n1p42

\begin{abstract}
Myxoedema coma is an uncommon and life-threatening endocrine emergency with a high mortality rate. This entity is the extreme expression of severe hypothyroidism and the cardinal features are decreased mental status and hypothermia. Diagnosis is challenging and a high index of suspicion is crucial because it allows an early recognition of this condition and prompt initiation of supportive measures along with adequate thyroid replacement therapy. Herein, we report an extremely rare case of myxoedema coma secondary to amiodarone in a 90-year-old female with no previous history of thyroid disease, which was successfully treated with thyroid hormone replacement. Although its rarity, we emphasize that myxoedema coma should be included in the differential diagnosis of consciousness disturbances, particularly in patients under amiodarone therapy.
\end{abstract}

Key Words: Myxoedema coma, Hypothyroidism, Amiodarone

\section{INTRODUCTION}

Amiodarone is an effective antiarrhythmic drug largely prescribed by clinicians worldwide. Thyroid dysfunction is one of the best known side effects of this agent, which can induce both hyper- and hypothyroidism. The incidence of amiodarone-induced hypothyroidism (AIH) is high, ranging from $2 \%$ to $34 \%$ according several studies. ${ }^{[1]}$ Older age, female gender, a pre-existing autoimmune thyroid disease with elevated baseline TSH levels, among others, are risk factors for the development of AIH. ${ }^{[1]}$ However, myxoedema coma (MC) secondary to amiodarone therapy has been sparsely reported. ${ }^{[1-5]}$ Although it is usually seen in patients with underlying thyroid disease, it can be the first manifestation of hypothyroidism. Due to its systemic involvement, the mortality rate is high (up to 50\%). Therefore, early diagnosis with prompt initiation of supportive measures and adequate thyroid replacement therapy, are of paramount importance in the management of this lethal endocrine emergency.

Herein, we report an uncommon case of amiodarone-induced myxoedema coma in a patient with no previous history of thyroid disease and make a review of the literature.

\section{CASE REPORT}

A 90-year-old Caucasian female was admitted in our Emergency Department due to a $24 \mathrm{~h}$ clinical picture of altered mental status with progressive mental confusion, reduction in motor coordination and drowsiness. During the early morning on the presenting day, she was found unconscious, lying on the floor.

Her medical history was remarkable for arterial hypertension, hyperlipidemia, coronary artery disease and paroxysmal

\footnotetext{
*Correspondence: Cláudio Martins; Email: cmartins1@campus.ul.pt; Address: Department of Gastroenterology, Setúbal Hospital Center, São Bernardo Hospital, Rua Camilo Castelo Branco, Setúbal 2910, Portugal.
} 
atrial fibrillation. There were no previous surgical history and no personal or family history of any thyroid disease. Her regular medication included ramipril $5 \mathrm{mg}$ daily, isosorbide mononitrate $20 \mathrm{mg}$ daily, aspirine $100 \mathrm{mg}$ daily, rosuvastatin $10 \mathrm{mg}$ daily, fluvoxamine $100 \mathrm{mg}$ daily and amiodarone $200 \mathrm{mg}$ daily.

On physical examination at admission, the patient was comatose with a Glasgow Coma Score of 8 (E2/V1/M5). Her vital signs revealed a blood pressure of $89 / 52 \mathrm{mmHg}$, body temperature of $95^{\circ} \mathrm{F}\left(35^{\circ} \mathrm{C}\right)$ according to a tympanic membrane thermometer, heart rate of 50 beats/minute and slow and shallow respiration (respiratory rate of 9 breaths/minute) with pulse oximetry of $88 \%$ with no oxygen supplementation. It was noted a cool and dry skin and generalized slight non-pitting oedema. Neurologic examination showed reactive pinpoint pupils and generalized hypotonia but with no apparent motor or sensory deficits, and negative Babinski reflex test. Inspection and palpation of the cervical region was performed and no goiter, neck stiffness or scars indicative of previous neck surgery were found. The remaining physical examination was unremarkable.

Initial laboratory evaluation revealed: haemoglobin $14.9 \mathrm{~g} / \mathrm{dl}$, WBC count 7,400/ $\mu \mathrm{l}$ (62\% neutrophils), CRP $0.14 \mathrm{mg} / \mathrm{dl}$, glucose $90 \mathrm{mg} / \mathrm{dl}$, Urea $43 \mathrm{mg} / \mathrm{dl}$, creatinin $0.9 \mathrm{mg} / \mathrm{dl}$, sodium $138 \mathrm{mEq} / \mathrm{L}$, potassium $4.1 \mathrm{mEq} / \mathrm{L}$, chloride $98 \mathrm{mEq} / \mathrm{L}$, calcium $9.3 \mathrm{mg} / \mathrm{dl}$, phosphate $3.60 \mathrm{mg} / \mathrm{dl}$, magnesium $2.40 \mathrm{mg} / \mathrm{dl}$, AST $28 \mathrm{IU} / \mathrm{L}$, ALT $26 \mathrm{IU} / \mathrm{L}$, AP $54 \mathrm{IU} / \mathrm{L}$, CK $126 \mathrm{IU} / \mathrm{L}$, troponin I $0.02 \mathrm{ng} / \mathrm{ml}$. Thyroid function was abnormal with thyroid-stimulating hormone (TSH) of $42.33 \mu \mathrm{IU} / \mathrm{ml}$ (N: 0.34-5.60) and free thyroxin (FT4) of $0.26 \mathrm{ng} / \mathrm{dl}(\mathrm{N}: 0.58-1.66)$. Arterial blood analysis $\left(\mathrm{FiO}_{2} 0.21\right)$ indicated $\mathrm{pH} 7.427, \mathrm{pCO}_{2} 51.6 \mathrm{mmHg}, \mathrm{pO}_{2} 58.4 \mathrm{mmHg}$, $\mathrm{HCO}^{3-}$ concentration $32 \mathrm{mmol} / \mathrm{L}$, lactate $1.3 \mathrm{mmol} / \mathrm{L}$ and an oxygen saturation of $89 \%$. Urinalysis did not show any signs of infection and urine drug screening tests were negative. ECG revealed sinus bradycardia, right bundle branch block and no evidence of acute ischemia. A portable chest $\mathrm{X}$-ray showed cardiomegaly, diffuse pulmonary oedema and mild bilateral pleural effusion. A computed tomography (CT) scan of the head without intravenous contrast did not revealed any signs of haemorrhage, acute ischemia, space occupying lesions, fluid or midline shift that could explain the rapid deterioration of consciousness.

The hypothesis of myxoedema coma was placed, thus, an attack dose of $200 \mathrm{mcg}$ of levothyroxine and $100 \mathrm{mg}$ of hydrocortisone was given, followed by maintenance of levothyroxine $100 \mathrm{mcg}$ orally once daily and hydrocortisone $100 \mathrm{mg}$ intravenously every $8 \mathrm{~h}$. After initiation of the above treatment, she showed marked hemodynamic and clinical improvement, as well as complete recovery of mental status. Amiodarone therapy was permanently discontinued after consulting with the cardiology team. FT4 after 3 days was normal. The patient was discharged home in stable condition and was referred to endocrinology consultation.

\section{Discussion}

$\mathrm{MC}$, the most severe expression of hypothyroidism, is a rare entity with a reported incidence rate of 0.22 per million per year. ${ }^{[6]} 80 \%$ of cases occur in elderly women, and there are a few cases reported on pregnant women. ${ }^{[6]}$

In the majority of cases, it results from any of the well known causes of primary hypothyroidism, particularly autoimmune thyroiditis, post-surgical (thyroidectomy) or post-ablative (treatment with radioactive iodine) hypothyroidism. In about $5 \%$ of cases it can be due to pituitary or hypothalamic failure (secondary hypothyroidism). ${ }^{[7]} \mathrm{MC}$ usually occurs as the culmination of long-standing hypothyroidism or can be precipitated by an acute event such as cerebrovascular accident, myocardial infarction, infection, cold exposure, or sedative drugs. There are a few case reports of its association with some drugs, namely sertraline, aripiprazole, lithium and amiodarone.

Amiodarone, a class III antiarrhythmic agent, is used worldwide to treat cardiac arrhythmias, such as atrial fibrillation, due to its low pro-arrhythmic potential and low negative inotropic effect, partic-ularly among patients with compromised ejection fraction. ${ }^{[8]}$ This drug is an iodinated derivative of ben-zofuran structurally similar to thyroid hormones which can induce hypo- or hypothyroidism. Amiodarone contains approximately $37 \%$ iodine by weight, is metabolised in the liver and has a mean elimination half-life of 40 days. A usual maintenance dose ranging from 100 to $600 \mathrm{mg}$ daily, generates 3-21 mg of free iodine which is 50-100 times greater than the recommended by World Health Organization. ${ }^{[9]}$ The pathophysiological mechanism of AIH seems to be the inability of thyroid gland to escape from the acute Wolf-Chaikoff effect after an iodine load. ${ }^{[9,10]}$ Due to this fact, AIH is more common in countries with high iodine intake (incidence of 13\%).

To our best knowledge, there are only five reported cases of amiodarone-induced myxoedema coma, and in two of them, the patients died despite adequate supportive measures and thyroid hormone replacement therapy (see Table 1). ${ }^{[1-5]}$ In this article, we describe a rare case of a MC in an elderly female under amiodarone therapy with no previous history of thyroid disease, which was successfully treated. 
Table 1. Amiodarone-induced myxoedema coma cases reported in the literature

\begin{tabular}{llllllll}
\hline Fist author & Gender & Age (years) & $\begin{array}{l}\text { Daily dose of } \\
\text { amiodarone }\end{array}$ & Duration on amiodarone therapy & $\begin{array}{l}\text { TSH levels } \\
(\boldsymbol{\mu I U} / \mathbf{m l})\end{array}$ & Outcome & Reference \\
\hline Mazonson PD & Male & 65 & $600 \mathrm{mg}$ & 5 months & 65.9 & Death & {$[2]$} \\
Shaheen M & Male & 67 & NM & NM & 166.66 & Death & {$[3]$} \\
Agarwal V & Male & 78 & NM & 5 months & 214.11 & Survival & {$[4]$} \\
Hassan S & Male & 62 & $400 \mathrm{mg}$ & 3 weeks & 168 & Survival & {$[5]$} \\
Chakraborty S & Female & 69 & $200 \mathrm{mg}$ & NM & 77.25 & Survival & {$[1]$} \\
\hline
\end{tabular}

Note. NM-non mentioned.

The two cardinal features of MC are decreased mental status and hypothermia. Despite the name, patients may not present in coma, but rather manifest less severe degrees of altered consciousness, such as lethargy and obtundation. ${ }^{[11]}$ Bradycardia, hypotension, hypoglycemia, hyponatremia, and hypoventilation with hypoxemia and hypercapnia are often present. The term myxoedema is due to abnormal deposits of mucin in the skin and other tissues, causing puffiness of the face, hands, legs and feet, thickened nose, swollen lips, and an enlarged tongue. ${ }^{[12]}$

The diagnosis of MC is based on history and physical examination, laboratory evaluation of thyroid function and exclusion of other causes of coma. If the suspicion of $\mathrm{MC}$ is high, a blood sample should be taken for evaluation of serum TSH, FT4 and cortisol prior to targeted therapy. Most patients with MC have primary hypothyroidism, with high serum TSH and low FT4. On the other hand, a normal or low serum TSH in a patient with a low FT4 indicates that the hypothyroidism is secondary to hypotha-lamic or pituitary dysfunction.

$\mathrm{MC}$ is a true endocrine emergency with a high mortality rate (up to $40 \%-50 \%$ ), and therefore the treatment of this disorder should be early and aggressive. ${ }^{[13]}$ Thyroid hormone replacement therapy is the cornerstone of treatment, as well as supportive measures and management of concomitant or precipitating disorders. The best thyroid hormone replacement therapy in $\mathrm{MC}$ remains a controversial area, due to lack of studies and evident difficulties in performing controlled trials. Currently, three different therapeutic regimens are described in the literature: oral or intravenous $\mathrm{T} 4$, intravenous $\mathrm{T} 3$ or a combination of $\mathrm{T} 4$ and $\mathrm{T} 3$. There are some considerations to take into account when choosing the best therapeutic approach: the greater biologic activity of $\mathrm{T} 3$ and its more rapid onset of action; peripheral conversion of T4 in T3 may be decreased in hypothyroidism and in any concurrent systemic diseases; and gastrointestinal absorption of T4 is variable and unpredictable. ${ }^{[14]}$ In addition, taking into account the risk of relative adrenal insufficiency, the patient must be treated with glucocorticoids in stress doses (e.g., intravenous hydrocortisone $100 \mathrm{mg} \mathrm{q} 8 \mathrm{~h}$ ). The reason for the concomitant treatment with glucocorticoids is the high risk of acute adrenal insufficiency secondary to the increased peripheral metabolism of cortisol that follows T4 supplementation.

In the presented case, the high clinical index of suspicion of MC (comatous patient with a cool and dry skin, generalized oedema, hypothermia, hypotension, bradycardia and hypoventilation with respiratory acidosis) led to an early recognition of this condition which was supported by the laboratorial study of thyroid function (low FT4 with high TSH, revealing primary hypothyroidism). The prompt initia-tion of supportive measures along with adequate thyroid replacement therapy and corticosteroids, were crucial to the success of the treatment.

Regarding AIH, the American Thyroid Association Taskforce on Hypothyroidism in Adults rec-ommends that patients should have a baseline TSH measurement before initiating amiodarone, with subsequent evaluation every 6 months. Current studies suggest that amiodarone can be held in patients under concomitant levothyroxine therapy. ${ }^{[1]}$

In conclusion, despite its rarity but considering the worldwide use of amiodarone as an anti-arrhythmic agent, we emphasize that amiodarone-induced myxoedema coma should be included in the differential diagnosis of consciousness disturbances. Although transient alterations may be seen in pa-tients under amiodarone therapy, close monitoring is crucial to look for clear changes in thyroid function. Our case highlights the need for greater awareness of the $\mathrm{AIH}$, in order to prevent MC, a life-threatening condition.

\section{CONFlicts OF INTEREST Disclosure}

The authors have no competing interests to declare. 


\section{REFERENCES}

[1] Chakraborty S, Fedderson J, Gums JJ, et al. Amiodarone-induced myxedema coma - a case and review of the literature. Arch Med Sci. 2014; 10(6): 1263-7. PMid:25624868 https://doi .org/10.511 4/aoms . 2013.35026

[2] Mazonson PD, Williams ML, Cantley LK, et al. Myxedema coma during long-term amiodarone therapy. Am J Med. 1984; 77: 751-4. https://doi.org/10.1016/0002-9343(84)90379-6

[3] Shaheen M. Severe congestive heart failure patient on amiodarone presenting with myxedemic coma: a case report. Indian Heart J. 2009; 61(4): 392-3. PMid:20635749

[4] Agarwal V, Parikh V, Otterbeck PE, et al. Myxedema coma induced by short-term amiodarone therapy. Am J Med Sci. 2014; 347(3): 2589. PMid:24521765 https ://doi.org/10.1097/MAJ . 00000000 00000241

[5] Hassan S, Ayoub W, Hassan M, et al. Amiodarone-induced myxoedema coma. BMJ Case Rep. 2014; 2014.

[6] Rodriguez I, Fluiters E, Perez-Mendez LF, et al. Factors associated with mortality of patients with myxedema coma: prospective study in 11 cases treated in a single institution. J Endocrinol. 2004; 80: 347-50. https://doi.org/10.1677/joe.0.1800347

[7] Mathew V, Misgar RA, Ghosh S, et al. Myxedema coma: a new look into an old crisis. J Thyroid Res. 2011; 2011: 493462. PMid:21941682 https : //doi.org/10.4061/2011/493462
[8] Plomp TA, van Rossum JM, Robles de Medina EO, et al. Pharmacokinetics and body distribu-tion of amiodarone in man. Arzneimittelforschung. 1984; 34: 513-20. PMid:6540111

[9] Martino E, Safran M, Aghini-Lombardi F, et al. Environmental iodine intake and thyroid dys-function during chronic amiodarone therapy. Ann Intern Med. 1984; 101: 28-34. PMid:6428291 https : //doi.org/10.7326/0003-4819-101-1-28

[10] Loh KC. Amiodarone-induced thyroid disorders: a clinical review. Postgrad Med J. 2000; 76(893): 133-40. PMid:10684321 https://doi.org/10.1136/pmj.76.893.133

[11] Kwaku MP, Burman KD. Myxedema coma. J Intensive Care Med. 2007; 22(4): 224-231. PMid:17712058 https://doi.org/10.1 $177 / 0885066607301361$

[12] Rosen M. Hypothyroidism. In: Marx J, editor, Rosen's emergency medicine; Concepts and Clin-ical practice. 5th ed. St. Louis, MO: Mosby Inc. 2002: 1774-9.

[13] Beynon J, Akhtar S, Kearney T. Predictors of outcome in myxoedema coma. Crit Care. 2008; 12(1): 111. PMid:18254932 https : //doi.org/10.1186/cc6218

[14] Wartofsky L, Burman KD. Alterations in thyroid function in patients with systemic illness: the 'euthyroid sick syndrome'. Endocr Rev. 1982; 3: 164-217. PMid:6806085 https ://doi.org/10.1210/ed rv-3-2-164 